\title{
Impact Evaluation of the New Self-Consumption Spanish Scenario on the Low Voltage Terminal Distribution Network
}

\author{
Pablo Arboleya, Arpan Koirala, Lucía Suárez, Bassam Mohamed, and Cristina González-Morán
}

\begin{abstract}
The recently approved regulation about SelfConsumption in Spain will change dramatically the level of penetration of photovoltaic distributed generation combined with storage devices at residential level in the short term. In the present paper, we will make a study to assess which is going to be the impact of the massive installation of such technologies under the constraints imposed by the new regulation over the terminal distribution network. As it will be demonstrated this impact will be drastic in terms of energy demand, voltage profile and load curves.
\end{abstract}

Index Terms-Self-Consumption, Prosumer, Low Voltage Distribution, Power Flow, Net Balance, Energy Storage, PV Generation, Electric Vehicles, Peer-to-peer, Blockchain, Energy Sharing, Prosumers.

\section{INTRODUCTION}

Self-consumption combined with energy storage has been recognized as one of the most efficient and reliable approaches to integrate renewable energy in terminal distribution systems [1]. Recently, many authors proposed techniques for integrating energy storage systems combined with photovoltaic (PV) generation at residential level.

Nearly 20 years ago, the term "Microgrid" was first introduced as the solution to managing portions of distribution networks where there was both consumption and distributed generation, usually with high renewable penetration [2]. Today, emerging technologies such as the Internet of Things (IoT) or Web of Things (WoT), BlockChain technology, the democratization of platforms for using BigData and Artificial Intenligence $(\mathrm{AI})$ and a reduction in costs in solar generation systems and energy storage systems [3], along with an increase in environmental awareness that has imposed major regulatory changes throughout the energy and transportation sectors are important revulsives that will somehow allow reinventing electricity distribution. New models will be generated and also very important business opportunities that, as a common denominator, will give a very active role to the so-called "prosumers".

Corresponding author email: arboleyapablo@uniovi.es

P. Arboleya, B. Mohamed and C. Gonzalez-Moran are with the Department of Electrical Engineering, University of Oviedo, Spain.

A. Koirala is with the ELECTA Group at the KU Leuven, Belgium

L. Suárez is Chief of Metering Infrastructure Systems at EDP, Spain

This work was partially supported by the Spanish Ministry of Economy and Competitivity under Grant MINECO-17-ENE2016-77919-R (CONCIALIATOR Energy conversion technologies in resilient hybrid AC/DC distribution networks). and by the Government of the Principality of Asturias - Foundation for Scientific and Technical Research (FICYT) under grant FCGRUPIN-IDI/2018/000241.
One of the cutting-edge concepts right now is the energy sharing among prosumers using the peer-to-peer concept. There are some pilot programs in this regard and many ongoing research related to this topic. A description of how the bilateral contracts could be implemented in order to deploy the peer-to-peer energy sharing can be found in [4], [5]. Other examples of clustering prosumers using PV generation and how the energy transactions between them can be implemented are described in [6], [7]. This change of paradigm will require a gradual adaptation of the distribution systems. It can be found in the literature some studies that try to quantify the impact over the distribution network of this "futuristic" systems [8], [9]. For instance, in [10], a very detailed analysis of the impact of PV-based residential system over the strategy of an electrical agregator is presented. In [11] the concept of virtual storage is analysed in order to deal with high levels of PV penetration in distribution networks.

It can be found in the literature many studies about which is going to be the impact of these new technologies and paradigms in the distribution network [12]. For each specific regulation and configuration an impact study must be carried out before the real deployment. For instance, the study presented in [13] is focused specifically on the influence of self-consumption on distribution network operation in the Slovenian case.

In some cases, the impact can be positive if all the resources are correctly sized and operated [1]. However it is prefectly demonstrated that the uncordinated penetration can create problems in the grid, as for instance, huge overvoltages in PV dominated distribution grids [14]. The study presented in [15] demonstrate the negative effect of the residential prosumers owning also EV fast chargers over the life of the distribution transformers. A probabilistic approach of the impact of PV system in a self-consumption scenario is developed in [15]. The authors in [16] proposes also an expansion planning methodology for distribution network depending on the selfconsumption penetration. Other operation proposals allow to coordinate prosumer's energy storage devices for providing ancillary services like voltage control [17].

There are also many studies proposing many kind of sophisticated methodologies for managing distributed resources, sizing and placing them for all kind of applications. Many of them use analytical or metaheurstic optimization procedures as it is the case of [18]. In [19], the selection of the battery sizes is calculated through an optimisation procedure considering the seasonal variation of the demand 
and generation in the prosumers and also the interaction between the low voltage and medium voltage networks. The study presented in [20] consider the interaction between the PV panels and storage systems but it also considers heat pumping. In [21], a building management system to coordinate electric loads, thermal loads and PV generation is proposed. In [22], the authors proposed an algorithm to plan the optimal charge and discharge schedule of the prosumer batteries in a microgrid. In the case presented in [23], the coordination is made at neighborhood level considering smart households comprising electric vehicles (EV), energy storage (ES) and photovoltaic generation. What all of these works have in common is the adoption of an optimization strategy that coordinates the different prosumers.

There is no doubt that the above mentioned approachs will set the tone in the medium/long term. However, in the short term, and in the vast majority of the cases, prosumers are installing the devices in an uncoordinated manner following selfish approaches and trying to maximize only their own benefit without considering any social welfare function.

The present paper aims to asses the impact of EV, PV and ES technologies over the distribution network in a very specific scenario, the new one created in Spain after the recently published Royal Decree that establish Urgent Measurements for Energy Transition and Consumer Protection [24]. It is expected that this regulation will create the conditions to drastically increase the penetration levels of photovoltaic systems combined with energy storage at domestic level. For carrying out this study, it has been considered that there is no coordination between the different households.

The paper is structured as follows. The following section briefly explains the new regulatory framework for selfconsumption in Spain and compares it with the previous situation. Section III explains the household electricity management system and section IV describes the scenarios considered for carrying out the study. In section $\mathrm{V}$ the results obtained will be presented and in section VI the authors will expound the conclusions of the study.

\section{Self-CONSUMption Spanish ScEnARio}

The Spanish scenario for Self-Consumption and Netbalance of consumers connected to the low voltage network changed drastically since October 6th, 2018 with the publication of the Royal Decree-Law 15/2018 [24]. The previous scenario was regulated through the Law 24/2013 of the Electric Sector [25] and multiple Royal Decrees among which the Royal Decree 900/2015 stands out [26]. Limitations imposed by the previous regulation prevented domestic consumers from mass installation of PV panels in combination with storage devices, even when the price of panels and batteries has been significantly reduced in recent years, along with an increase in efficiency.

The new regulation establishes two modes of selfconsumption depending on whether or not there is a physical device that prevents the injection of excess energy into the network. In the first case, the whole installation can be considered as a consumer and the administrative burden for

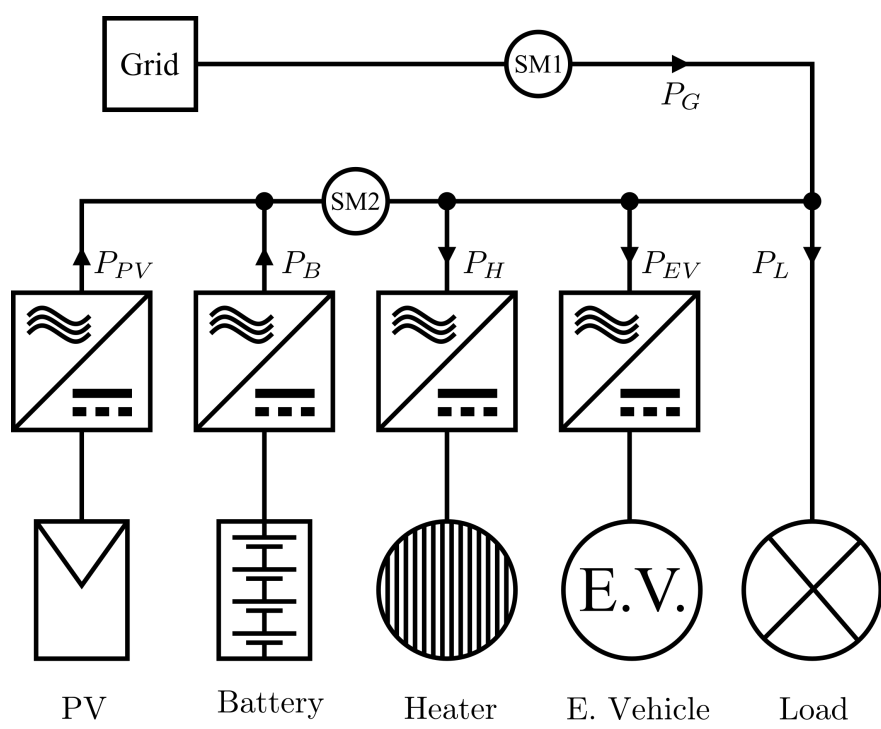

Fig. 1: Simplified scheme of a dwelling electrical installation including PV panels, batteries, controllable electrical water heater, electrical vehicle charger and the conventional load.

the legalization of the system is very small. For this reason, the vast majority of households are expected to use this system in the near future. The second mode allows the injection of surplus energy, but in this case, the electrical installation must be divided into two from the administrative point of view (Consumer and Producer).

In order to explain the actual conditions and the improvement with respect to the previous situation from the point of view of the domestic consumer, we are going to consider a simplified scheme like the one depicted in Fig. 1. In the previous scenario, it was mandatory the use of two different smart meter devices (labeled in the 1 as SM1 and SM2). The first device (SM1) read the total net power injected and consumed from the network. The second device reads the net power of the set (PV panels + batteries). Negative readings were not allowed on SM2, so the battery could only be charged with energy from the PV panels.

There was also a restriction imposing that the contracted power at the point of SM1 should be greater than or equal to the installed power. This limitation was repealed with the new Regulation. In the previous situation, if we installed PV panels with a peak power of $10 \mathrm{~kW}$, we should contract $10 \mathrm{~kW}$ for the consumer even if it is not necessary. It should be noted that the electricity bill in Spain is binomial, with one term depending on the energy consumed and another depending on the contracted power. This second term can be very important and in the previous situation it was not possible to reduce it through the installation of PV panels or accumulation systems.

In addition to the energy and power terms, the prosumers as well as the rest of the agents in the system must collaborate to maintain the electrical system. For this reason it is necessary to pay extra charges and tolls for using the grid. We have two kinds of charges, the fixed and the variable ones. The fixed charges usually depend on the contracted power. The 


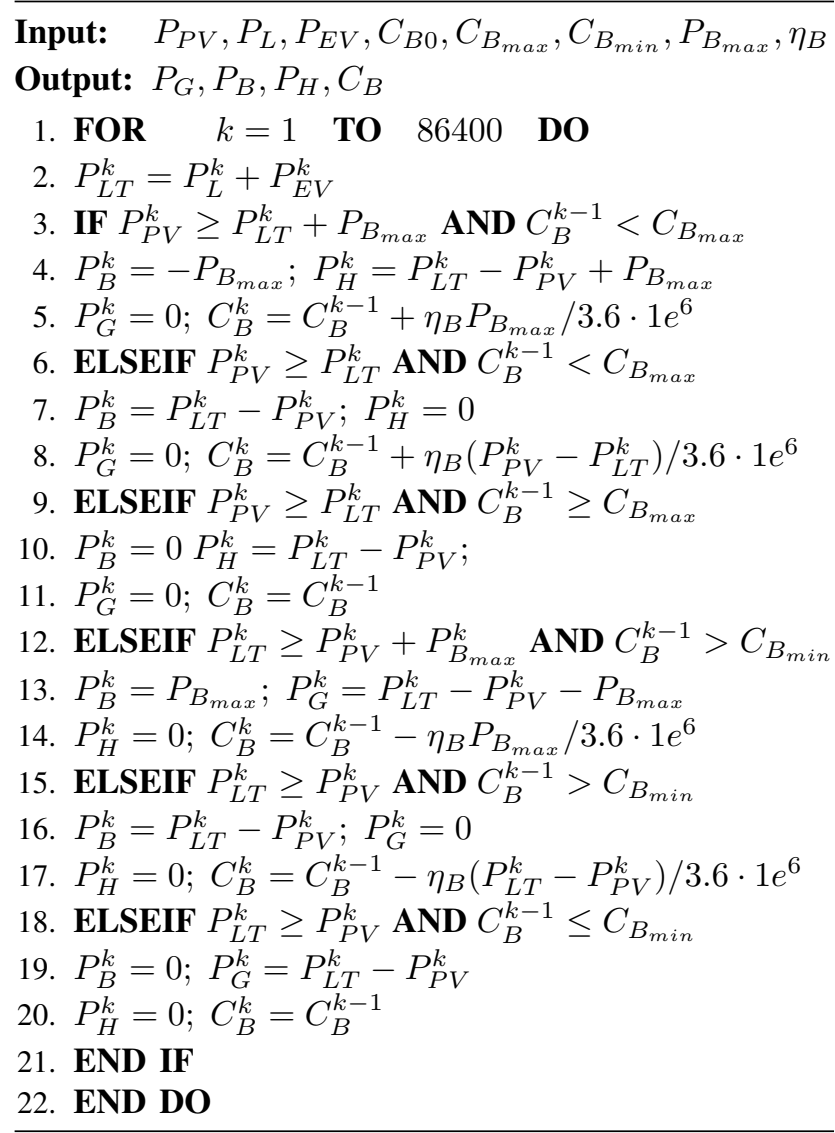

Algorithm 1: Battery Management Algorithm

previous situation made nearly impossible to reduce this term since it was not possible to reduce the contracted power. The variable charges were affected by the energy demanded by the consumer as well as the self-consumed energy. The payment of this variable charge depending on the self-consumed energy was really unpopular, and generally known as "sun tax". In the new scenario, this tax has been revoked and the users can contract the power that they really need independently from the installed generation capacity. From now on, we will adopt the first mode in which a physical device prevents the injection of excess power into the grid.

\section{Household Energy Management System}

In Fig. 1, the simplified diagram of each household is depicted. The load profiles were extracted from project ADRES-CONCEPT [27]. This project provides real power consumption profiles of 30 different households in upperAustria during 7 winter days and 7 summer days, a total of 420 daily power profiles sampled with 1 second resolution. The base consumption of each of the houses in this study was obtained from one of the above-mentioned profiles and it is represented by $P_{L}$. Additionally, it has been considered that each house is equipped with an electric car charger. We considered that the average driver in Spain makes $45 \mathrm{~km}$ per day. The number of kilometres driven by the electric car on the previous day was calculated using a random function with an average value of $45 \mathrm{~km}$. The charger is protected with a
TABLE I: Comparison of the aggregated values obtained for summer and winter in the household represented in Fig. 2.

\begin{tabular}{l|c|c} 
& Summer & Winter \\
\hline \hline$P_{L T}($ Average) $(\mathrm{W})$ & 737.8 & 897.4 \\
$P_{L T}($ Max) $(\mathrm{W})$ & 6902.7 & 5230.8 \\
$P_{L}$ (Average) $(\mathrm{W})$ & 987.9 & 1203.7 \\
$P_{L}($ Max) $(\mathrm{W})$ & 6902.7 & 6638.1 \\
$P_{G}($ Average $)(\mathrm{W})$ & 158.6 & 698.1 \\
$P_{G}($ Max) $(\mathrm{W})$ & 5640.8 & 6638.1 \\
$P_{P V}($ Average $)(\mathrm{W})$ & 1118.2 & 505.5 \\
$P_{P V}($ Max) $(\mathrm{W})$ & 3107.6 & 2150.2 \\
$P_{B}$ when $\left(P_{B}>0\right.$ (Average) $(\mathrm{W})$ & 442.4 & 229.7 \\
$P_{B}$ when $\left(P_{B}<0\right.$ (Average) $(\mathrm{W})$ & -418.6 & -229.7 \\
$E_{L T}(\mathrm{kWh})$ & 23.7 & 28.9 \\
$E_{L}(\mathrm{kWh})$ & 17.7 & 21.5 \\
$E_{G}(\mathrm{kWh})$ & 3.8 & 16.7 \\
$E_{P V}(\mathrm{kWh})$ & 26.8 & 12.1 \\
$E_{B}$ when $\left(P_{B}>0\right)(\mathrm{kWh})$ & 10.6 & 7.2 \\
$E_{B}$ when $\left(P_{B}<0\right)(\mathrm{kWh})$ & -10.1 & -7.2 \\
$E_{H}(\mathrm{kWh})$ & 7.5 & 0
\end{tabular}

$32 \mathrm{~A}$ breaker but its power is limited to $5200 \mathrm{~W}$. All cars start the charging process at a random hour between midnight and 03:00 a.m. The charging power is represented by $P_{E V}$.

In the present document, we will consider different levels of penetration of houses that use solar panels combined with accumulation systems. In such cases, we assume that consumers are adopting mode 1 described in the previous section, so they have a physical device that prevents the injection of excess power into the network. In this case, this device has been modeled as a thermal device but it could be a system that reduce the power reference provided to the PV converter. The power surplus has been denoted by $P_{H}$.

For the calculation of $\mathrm{PV}$ production it has been considered that each house can be equipped with photovoltaic panels with a peak power of $3200 \mathrm{~W}$. The theoretical radiation was obtained for Gijón (A city in northern Spain) according to the model proposed by ASHRAE [28]. The power generated by the PV panels is labeled as $P_{P V}$. When a household is equipped with PV and battery, the battery selected was the LG RESU 10LV. This battery has a capacity of $10 \mathrm{kWh}$ with a total energy usage of $85 \%$ and a rated charge and discharge power of $5 \mathrm{~kW}$. The power in the battery is considered positive in discharging mode and it is denoted as $P_{B}$. A markov based weather model has been incorporated in order to simulate three different scenarios [29]. For a specific day in summer or winter, we consider also three conditions (sunny, cloudy, heavy clouds).

The coordination between the different systems is described in Algorithm 1. The authors are fully aware that this is not the optimum strategy nor for the consumers neither for the distribution system, however it is the strategy followed by most of commercial systems and it is expected that this situation will continue at least in the mid term. For this reason, we will consider this non-optimal conditions in order to evaluate the impact of the system in the network. $C_{B 0}, C_{B}, C_{B_{\max }}$ and $C_{B_{\min }}$ represent respectively the initial, actual, maximum 

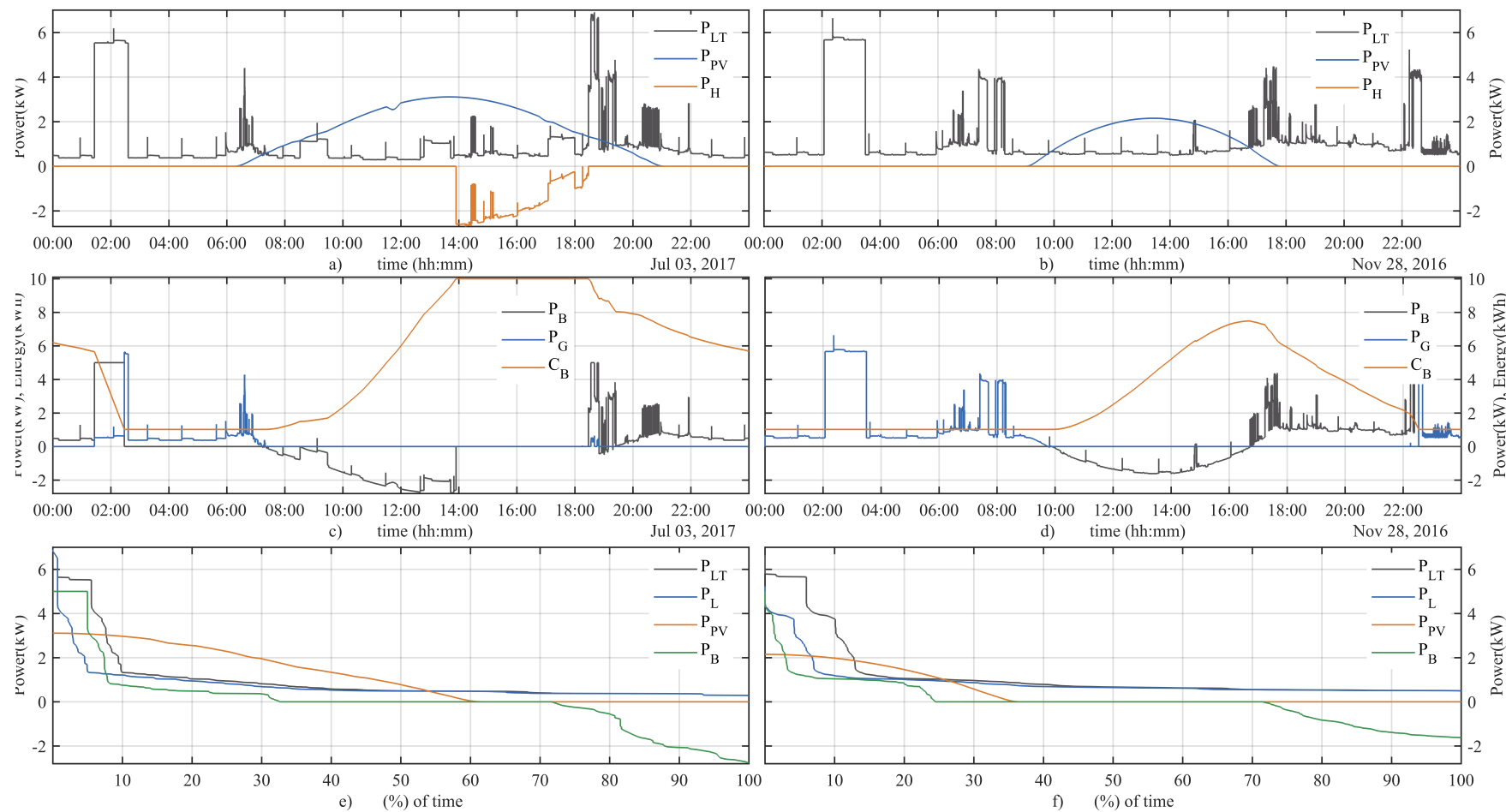

Fig. 2: Case of study of a specific household. Subfigures a), c) and e) represent a summer day while subfigures b), d) and f) represent a winter day. Subfigures a) and b) represent the total power consumption $\left(P_{L T}\right)$, the power generated by the PV panels $\left(P_{P V}\right)$ and the power "burned" by the physical device that prevents from the grid injection $\left(P_{H}\right)$. Subfigures c) and d) represent the power of the battery $\left(P_{B}\right)$, the power imported from the grid $\left(P_{G}\right)$ and the state of charge of the battery $\left(C_{B}\right)$. Subfigures e) and f) are the load duration curves containing the sorted values of all powers.

and minimum state of charge of the battery. $\eta_{B}$ stands for the efficiency of the battery (90\%) and $P_{L T}$ is the total load considering the conventional household consumption plus the EV charger. As it can be observed in the Algorithm 1, the system assigns priority to the load and after that to the battery. We have different scenarios described in the algorithm but basically:

- If the PV panel produces enough energy to feed the load, the extra power is used to charge the battery (if is not full), if the battery is full or the extra power is greater

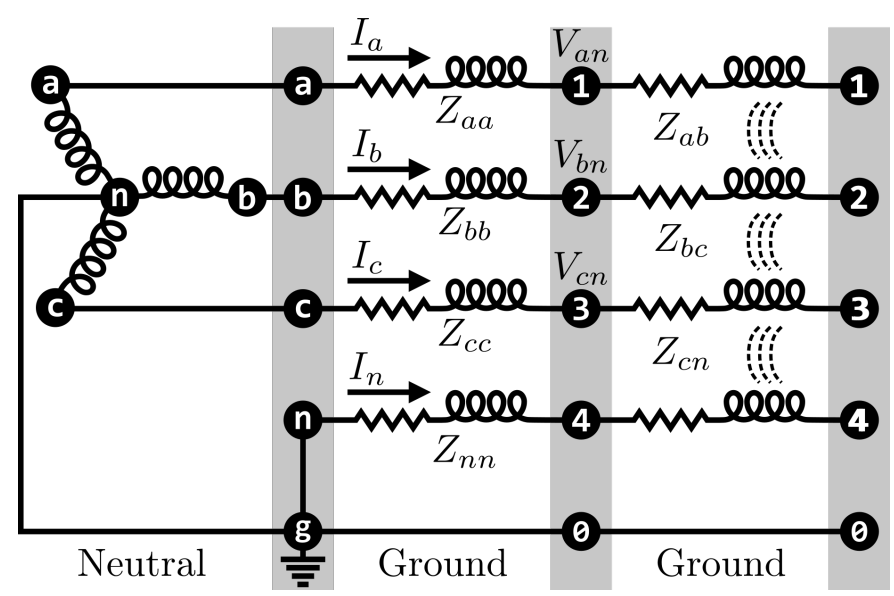

Fig. 3: TT grounding scheme than the maximum charging power of the battery, the surplus is used for the heater

- If the PV panel does not produce enough energy to feed the load, the required extra power is obtained from the battery if it is not empty or the required extra power is greater than the maximum discharge power of the battery, the power deficit is obtained from the grid.

In Fig. 2, the behaviour of a specific household during a summer day and a winter day can be compared. As it can be observed, in the summer day the battery is full at 14:00 hours, so the physical device that prevents injection into the network is "wasting" energy for about 4 hours. This is only in the most favourable case on a sunny summer day with moderate consumption. Installing a battery with more capacity is not a good option as most days we will not have this behavior. For instance, on a sunny winter day the maximum level of charge of the battery does not reach $80 \%$ of its capacity. During the summer day (best scenario) the home is self-sufficient for almost 18 hours, during the winter day this interval drops to 12 hours. On a summer day, the battery charge level allows the user to charge a significant percentage of the EV battery during the night, while the battery charge level at the end of the winter day is nearly always the minimum. Table I contains the maximum and average powers during the summer and winter day for the same house represented in Fig. 2 and also the aggregated energies. It must be noted that, as it was expected, the average power consumption during the winter 
TABLE II: Summary of the behavior of 5 houses placed at nodes 3, 10, 35, 49 and 53 with and without prosumer set installation in the different weather and seasonal scenarios.

\begin{tabular}{|c|c|c|c|c|c|c|c|c|c|}
\hline \multirow{2}{*}{$\begin{array}{l}\text { Season } \\
\text { Weather } \\
\text { Scenario }\end{array}$} & \multicolumn{4}{|c|}{ Summer } & \multicolumn{4}{|c|}{ Winter } & \multirow[b]{2}{*}{ House } \\
\hline & Load & $\begin{array}{c}\text { Sunny } \\
\text { Load+Sys }\end{array}$ & $\begin{array}{c}\text { Cloudy } \\
\text { Load+Sys }\end{array}$ & $\begin{array}{l}\text { Heavy Cl. } \\
\text { Load+Sys }\end{array}$ & Load & $\begin{array}{c}\text { Sunny } \\
\text { Load+Sys }\end{array}$ & $\begin{array}{c}\text { Cloudy } \\
\text { Load+Sys }\end{array}$ & $\begin{array}{l}\text { Heavy Cl. } \\
\text { Load+Sys }\end{array}$ & \\
\hline $\begin{array}{l}\text { Net Energy }(\mathrm{kWh}) \\
\text { Maximum Power }(\mathrm{kW}) \\
\text { Average power }(\mathrm{kW})\end{array}$ & $\begin{array}{c}17,9 \\
7,8 \\
0,7\end{array}$ & $\begin{array}{l}4,0 \\
5,7 \\
0,2\end{array}$ & $\begin{array}{l}6,8 \\
6,6 \\
0,3\end{array}$ & $\begin{array}{l}8,4 \\
6,4 \\
0,4\end{array}$ & $\begin{array}{c}22,3 \\
6,3 \\
0,9\end{array}$ & $\begin{array}{c}12,1 \\
6,3 \\
0,5\end{array}$ & $\begin{array}{c}13,2 \\
6,4 \\
0,6\end{array}$ & $\begin{array}{c}16,9 \\
6,4 \\
0,7\end{array}$ & Node 35 \\
\hline
\end{tabular}



Fig. 4: IEEE European Low Voltage Test Feeder modified for TT distribution systems

day is slightly higher than during the summer day. However, the average power obtained from the grid in the summer is just $158.6 \mathrm{~W}$ versus the $698.1 \mathrm{~W}$ of average power consumed during the winter day.

\section{Proposed SCEnARIOS}

In order to evaluate the impact on the grid, the IEEE European Low Voltage Test Feeder was selected. As it was mentioned, the loads were substituted by the ones provided by ADRES project and also the lines were modified considering a 4 wire system in order to represent better the European terminal distribution networks with a TT grounding system.
The TT grounding system is represented in Fig. 3, the neutral wire is grounded at transformer level and the grounds in the different households are not participating in the electric scheme unless there is a fault in the system. In the original test feeder, only three wires are considered. It should be noted that when Kron reduction is applied to transform a 4-wire system into a 3-wire system, it is assumed that the neutral is grounded at each node, which is far from representing reality in TT systems, as will be demonstrated later.

The 420 load profiles provided in the ADRES database are randomly assigned to the 55 load nodes present in the IEEE Low Voltage test feeder represented in Fig. 4. A set of 30 different scenarios was generated. We considered two different prototype days, summer day and winter day, as a summer day July $3^{r d}$ of 2017 was considered and as a winter day we selected November $28^{\text {th }}$ of 2016 . For each day we simulate the three wather conditions (Sunny, Cloudy and Heavy Cloud) and for each combination of season plus weather we obtain the results with 5 levels of penetration for houses with a "prosumer system" (PV panels combined with batteries) $(0 \%, 25 \%, 50 \%$, $75 \%$ and $100 \%)$.

\section{AnAlysis OF THE RESUlts}

A first analysis is made to 5 individual prosumers placed at nodes $3,10,35,49$ and 53 . Nodes 3 and 49 are connected to the phase A, nodes 10 and 35 are connected to the phase B and node 53 is connected to the phase C. Table II summarizes the behaviour of the 5 houses for all possible combinations of season and weahter conditions in conventional mode (Load) and in prosumer mode (Load+Sys), this last case consider the battery, the EV and the PV installation. The table provides data about the net energy absorbed from the grid in each house, the maximum power and the average power during the day. As it 


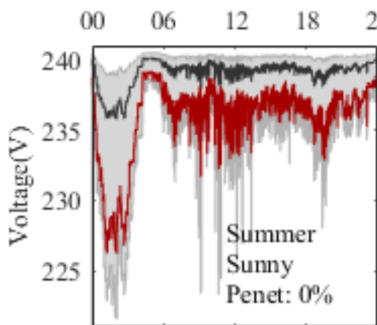

a)

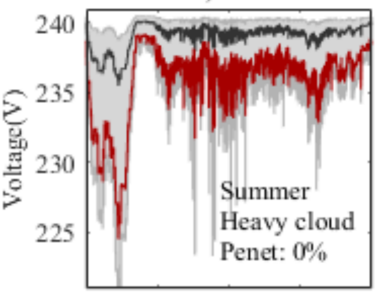

f)

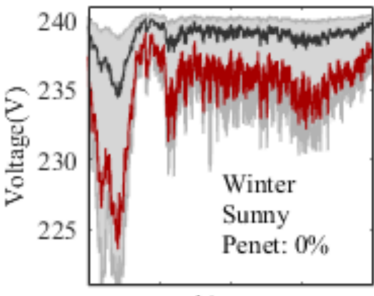

k)

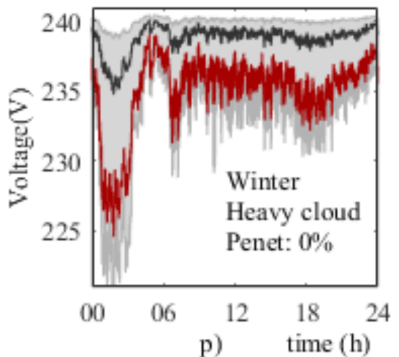

$24 \quad 00$

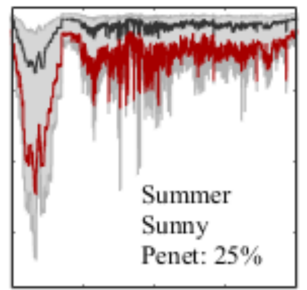

b)

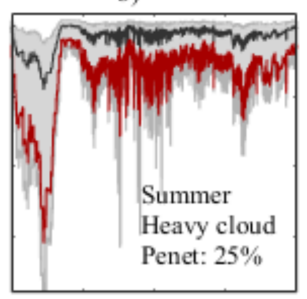

g)

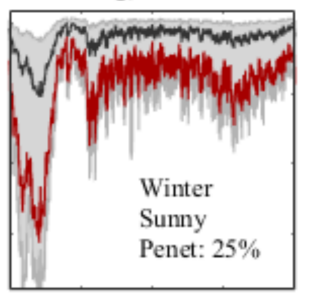

1)

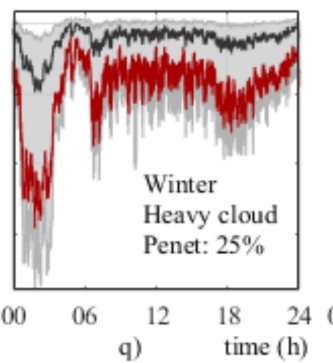

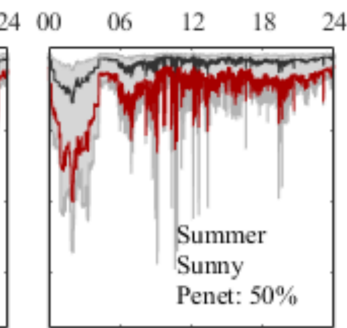

c)

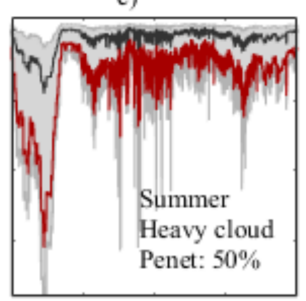

h)

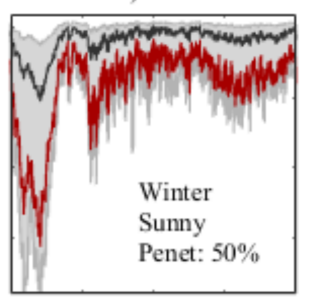

m)

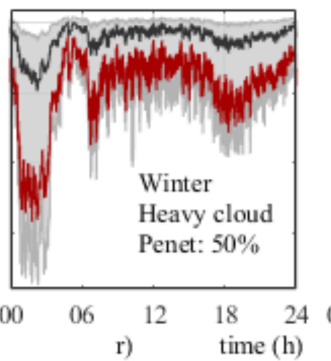

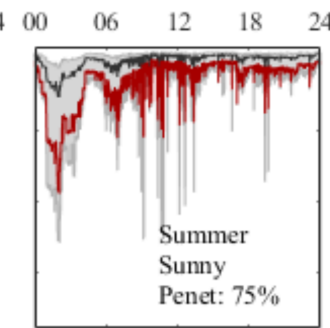

d)

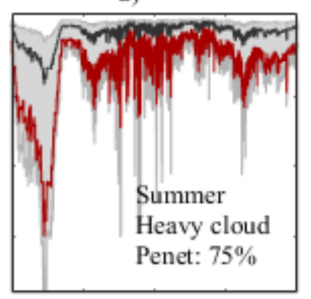

i)

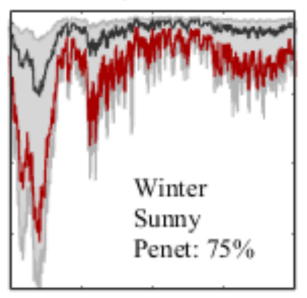

n)

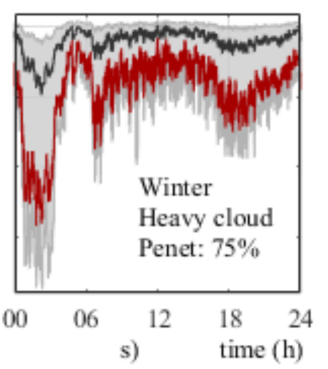

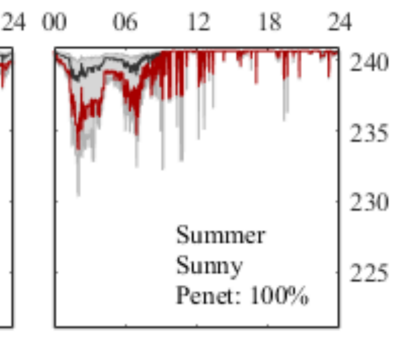

e)

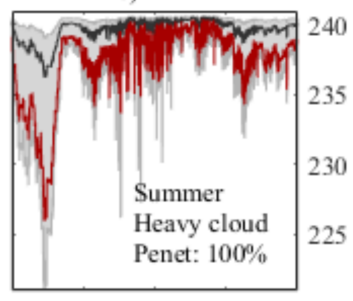

j)

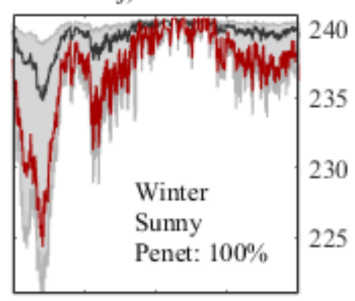

o)

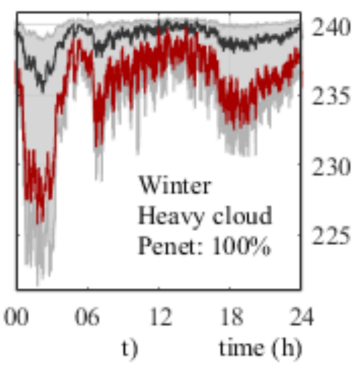

Fig. 5: Voltages in the nodes in the different scenarios. First two rows represent the summer scenarios in sunny (first row) and heavy cloud conditions (second row). The rows 3 and 4 represent the winter scenario in sunny and heavy cloud conditions respectively. Columns 1 to 5 represent respectively the five levels of penetration of households with PV and batteries from $0 \%$ to $100 \%$. The grey color represents the voltage involute that contains the voltage in all the nodes of the system. In black, the voltage in the home placed at node 3 and in red the voltage in the house placed at node 53.

can be observed not all the houses behave in the same way, some of them increase the consumption in a typical winter day, like for instance houses in nodes 35 or 53, or even more, house in node 10 that has a net consumption in the summer of $19.4 \mathrm{kWh}$ that rises to $66.3 \mathrm{kWh}$ during in the winter. Other houses like the house connected in node 49 have a significant consumption reduction in winter days. A reduction of the consumption in winter days can be observed also in the house connected in node 3 , but in this last case this reduction is just around $1 \mathrm{kWh}$. It is interesting to analyse the significant net demand reduction when the prosumer system is installed in all cases for summer days and how this reduction is affected by the weather conditions. The influence of the weather does not have the same impact in all cases because it is also very important the consumption pattern of the different users. For instance, in the house of the node 49, in a winter day the net energy consumption in a heavy cloud condition decreases from $25.4 \mathrm{kWh}$ to $22.8 \mathrm{kWh}$, just $10 \%$ of reduction $(2.6 \mathrm{kWh})$. The house in the node 3 , has a reduction from $26.1 \mathrm{kWh}$ to $17.7 \mathrm{kWh}$, which represent a $32 \%$, and if we analyse the house number 53, this time in summer, we observe that installing the prosumer equipment can make the house nearly self sufficient in sunny and cloudy days and the reduction of the demand in a heavy cloud day is really important passing from $20.8 \mathrm{kWh}$ to $7.1 \mathrm{kWh}$, a reduction of $65 \%$. In Fig. 5, we can observe the impact of the different scenarios in the voltage profile. In the first two rows we can observe the summer scenarios with the sunny day in the first raw and the heavy cloud day in the second. In the same way the rows 3 and 4 represent the sunny winter scenario and the heavy cloud winter scenario. The grey envolute represent the maximum and minimum voltage in all the phases and all the nodes of the grid. The voltage in houses placed at node 3 and node 53 is represented in black and red respectively. The best situation in terms of voltage 

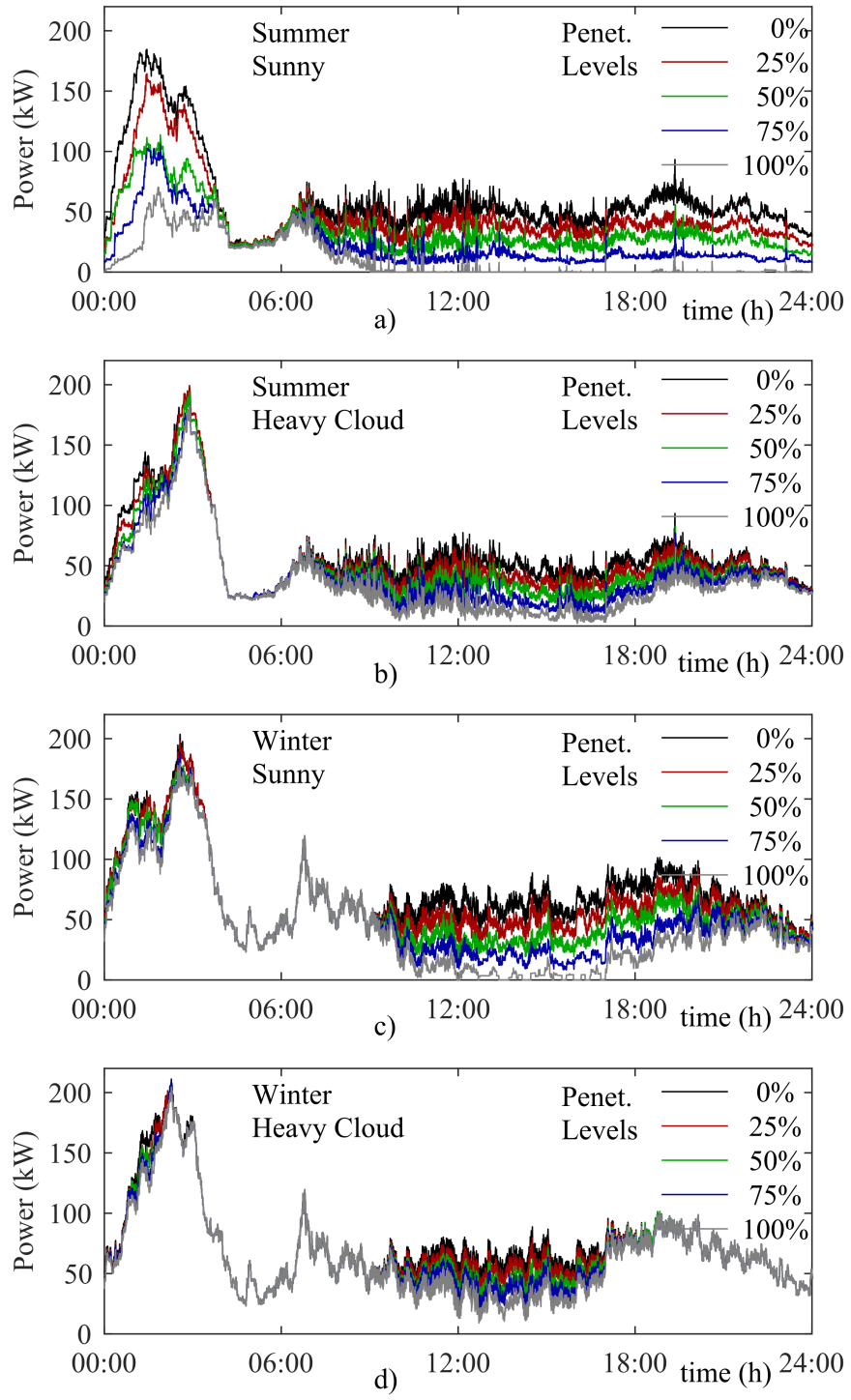

Fig. 6: Level of load at the power transformer at all penetration levels $(0 \%, 25 \%, 50 \%, 75 \%$ and $100 \%)$. a) Summer sunny scenario. b) Summer heavy cloud scenario. c) Winter sunny scenario. d) Winter heavy cloud scenario.

profile is obviously in the $100 \%$ penetration scenario during a summer sunny day. This is the only case that really mitigates the effect of the EV chargers during the night, and it creates a nearly plain voltage profile during the day. In the rest of the cases, the strategy of concentrate the EV charging during the night creates an important voltage drop in the system. It is also interesting to evaluate and quantify the voltage drop correlation with the weather and season conditions. As it can be observed, even in the worst scenario, winter and heavy cloud day, the effect of the prosumers is not negligible.

Fig. 6 represent the load of the system measured at the substation level in different scenarios, only sunny and heavy cloud days have been depicted in summer and winter scenarios considering all penetration levels. It is worth to mention that only in the sunny summer scenario the increasing in the penetration level has a significant impact in the load reduction during the night due to the EV chargers. This is because only in sunny summer days the batteries at midnight have a significant amount of energy that can be used to charge the vehicles, in the rest of the cases, the charge during the night provokes a peak power at the power transformer that cannot be mitigated adding PV generation or energy storage in the grid, at least in the way defined by the new Spanish regulation. During the day, the effect of the penetration in all cases is clear. Obviously it is more drastic in summer sunny days, when the system is nearly self-sufficient from 09:00 to 24:00. In winter heavy cloud days the impact of the prosumers is only important in the interval from 10:00 to 17:00.

The graphic representation is very important to provide a first analysis of what is happening in the system. However, a very interesting quantification is presented in the table III. In this table we provide data about the net energy and average power in different points of the network (The nodes S, A, B and $\mathrm{C}$ of Fig 4). Al season, weather and penetration levels are considered. Analysing the data obtained at substation level, we can observe that in this case, the consumption increases clearly during the winter days from $1454 \mathrm{kWh}$ to $1765 \mathrm{kWh}$. In the summer scenario, the energy reduction varies in a range from $10 \%$ in a heavy cloud day with the $25 \%$ of penetration (with $1304 \mathrm{kWh}$ ) to $82 \%$ in the best case scenario (sunny with $100 \%$ penetration) with a demand of only $258 \mathrm{kWh}$ at substation level. The energy reduction varies nearly in a linear way with the level of penetration, so even in a small case of a single power transformer with 55 loads with quite different behavior the aggregated behaviour of all of them can be estimated using a linear model. Analysing how the weather affects to a specific day with the same level of penetration we can observe for instance that in a summer sunny day with $25 \%$ of penetration, the energy provided to the system is $1136 \mathrm{kWh}$, and it increases only $4 \%$ if the day is cloudy and $14 \%$ if we have a heavy cloud day. These variations are non extrapolable to other scenarios. For instance, in the same day (summer), with a $100 \%$ of penetration, the energy provided to the system in a sunny day is $258 \mathrm{kWh}$ and in a cloudy day increases $51 \%$, in a heavy cloud day it increases $243 \%$ up to $887 \mathrm{kWh}$. The energy increasing proportions for a given day due to the poor weather conditions are maintained in all the points of the network (A, B and C). The number of houses downstreams points $\mathrm{A}, \mathrm{B}$ and $\mathrm{C}$ is respectively 43,13 and 8 . The behavior of the system during the winter is quite different since the energy increase due to the weather conditions is not so drastic neither in absolute or relative terms. For instance, in a winter day, the substation provides $1765 \mathrm{kWh}$ with $0 \%$ penetration and $1594 \mathrm{kWh}$ with $25 \%$ penetration in a sunny day, a total reduction of around $10 \%$. When comparing a cloudy day with a sunny day we can see that the energy increase is only $3 \%$, and comparing a heavy cloud day with a sunny day the energy increase is around 6\%. With a $100 \%$ of penetration level, the energy provided to the system in a sunny day is $1047 \mathrm{kWh}$, a reduction of $40 \%$. Comparing a cloudy day with a sunny day the energy increase is around $20 \%$, and if we make the comparison between the heavy cloud and the sunny day the increase is $44 \%$. We observe that, obviously the weather affects more the scenarios with high penetration levels but the 
TABLE III: Quantification of the prosumers penetration level impact in different points of the network (Substation and points A, B and C of the modified IEEE European Low Voltage Distribution test feeder represented in 4). All weather, seasonal and penetration combinations were considered. We used the next abrevaiations. Sun.: Sunny, Clo.:Cloudy and H.Clo.:Heavy Cloud.

\begin{tabular}{|c|c|c|c|c|c|c|c|c|c|c|c|c|c|c|}
\hline \multirow{2}{*}{$\begin{array}{l}\text { Season } \\
\text { Penetration }\end{array}$} & \multicolumn{13}{|c|}{ Summer } & \multirow{5}{*}{ 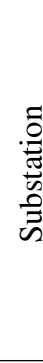 } \\
\hline & $0 \%$ & \multicolumn{3}{|c|}{$25 \%$} & \multicolumn{3}{|c|}{$50 \%$} & \multicolumn{3}{|c|}{$75 \%$} & \multicolumn{3}{|c|}{$100 \%$} & \\
\hline $\begin{array}{l}\text { Wheather } \\
\text { Energy (kWh) }\end{array}$ & 1454 & $\begin{array}{l}\text { Sun. } \\
1136\end{array}$ & $\begin{array}{l}\text { Clo. } \\
1182\end{array}$ & $\begin{array}{c}\text { H.Clo. } \\
1304\end{array}$ & $\begin{array}{l}\text { Sun. } \\
834\end{array}$ & $\begin{array}{l}\text { Clo. } \\
912\end{array}$ & $\begin{array}{c}\text { H.Clo. } \\
1161\end{array}$ & $\begin{array}{c}\text { Sun. } \\
544\end{array}$ & $\begin{array}{l}\text { Clo. } \\
642\end{array}$ & $\begin{array}{c}\text { H.Clo. } \\
1022\end{array}$ & $\begin{array}{l}\text { Sun. } \\
258\end{array}$ & $\begin{array}{l}\text { Clo. } \\
390\end{array}$ & $\begin{array}{c}\text { H.Clo. } \\
887\end{array}$ & \\
\hline Av. power $(\mathrm{kW})$ & 61 & 47 & 49 & 54 & 35 & 38 & 48 & 23 & 27 & 43 & 11 & 16 & 37 & \\
\hline Season & \multicolumn{13}{|c|}{ Winter } & \\
\hline Season & \multicolumn{13}{|c|}{ Summer } & \multirow{4}{*}{$\begin{array}{l}4 \\
\text { Z } \\
Z\end{array}$} \\
\hline Energy $(\mathrm{kWh})$ & 1289 & 1017 & 1060 & 1170 & 763 & 835 & 1061 & 514 & 607 & 955 & 231 & 358 & 821 & \\
\hline Av. power $(\mathrm{kW})$ & 54 & 42 & 44 & 49 & 32 & 35 & 44 & 21 & 25 & 40 & 10 & 15 & 34 & \\
\hline Season & \multicolumn{13}{|c|}{ Winter } & \\
\hline Energy $(\mathrm{kWh})$ & 949 & 736 & 777 & 865 & 579 & 643 & 797 & 312 & 392 & 682 & 170 & 279 & 624 & \multirow{5}{*}{$\begin{array}{l}n \\
\frac{8}{8} \\
\text { Z }\end{array}$} \\
\hline Av. power $(\mathrm{kW})$ & 40 & 31 & 32 & 36 & 24 & 27 & 33 & 13 & 16 & 28 & 7 & 12 & 26 & \\
\hline Season & \multicolumn{13}{|c|}{ Winter } & \\
\hline Energy $(\mathrm{kWh})$ & 1107 & 1003 & 1036 & 1079 & 904 & 964 & 1045 & 747 & 861 & 1005 & 665 & 798 & 978 & \\
\hline Av. power $(\mathrm{kW})$ & 46 & 42 & 43 & 45 & 38 & 40 & 44 & 31 & 36 & 42 & 28 & 33 & 41 & \\
\hline Season & \multicolumn{13}{|c|}{ Summer } & \multirow{4}{*}{$\begin{array}{l}U \\
8 \\
0 \\
Z\end{array}$} \\
\hline Energy (kWh) & 227 & 160 & 174 & 196 & 87 & 112 & 173 & 66 & 91 & 161 & 47 & 78 & 151 & \\
\hline Av. power $(\mathrm{kW})$ & 9 & 7 & 7 & 8 & 4 & 5 & 7 & 3 & 4 & 7 & 2 & 3 & 6 & \\
\hline Season & \multicolumn{13}{|c|}{ Winter } & \\
\hline
\end{tabular}

impact is much more dramatic during the summer days.

In Fig 7, the neutral voltage in the house located in node 53 is represented for all scenarios in sunny and heavy cloud conditions. As it can be observed, the effect of increasing the prosumers penetration over the neutral voltage is nearly negligible in heavy cloud scenarios. In the sunny scenarios a reduction is observed during the day (from 9:00 to 24:00 in summer and from 10:00 to 17:00 in winter). However, during the night and due to the EV charging, there is no significant neutral voltage reduction, the same effect was observed in the power analysed in Fig 6. Neutral voltage issues can have extraordinary importance in terminal distribution systems, the modification of the IEEE Low Voltage Distribution Test feeder for study this problems is a mandatory task in order to avoid the use of the Kron reduction for obtaining an equivalent 3 wires system.

\section{CONCLUSIONS AND FUTURE WORKS}

In this paper, it was demonstrated that the new Spanish Self-Consumption regulation will have a drastic impact on the network reducing the total demand. These kind of studies are of significant importance in order to estimate not only the economic impact of new regulations over the systems but also the technical impacts. As in this specific case, the conditions for simulating the different scenarios must emulate the regulatory and technical conditions of the real cases. It was demonstrated that energy savings can be higher than $80 \%$ in the best case scenario (sunny summer day) and around $12 \%$ in the worst case scenario (Heavy cloud winter day) when the penetration is $100 \%$. It has been also demonstrated that for a specific day (weather and season) the energy reduction varies linearly and inversely proportional to the level of penetration. In the case that the EVs are charged during the night, it will be impossible to reduce the maximum power at substation level. Incentive policies to coordinate storage systems could benefit both consumers and distributors. In the short term, more studies should be conducted on more complex scenarios in order to design incentives to coordinate devices appropriately. In the mid and long term technologies like the peer-to-peer energy trading will change completely the role of the prosumers within the systems. The impact studies for considering this peer-to-peer energy sharing should include not only technical variables but also social variables to model the possible behavior of the prosumers. 

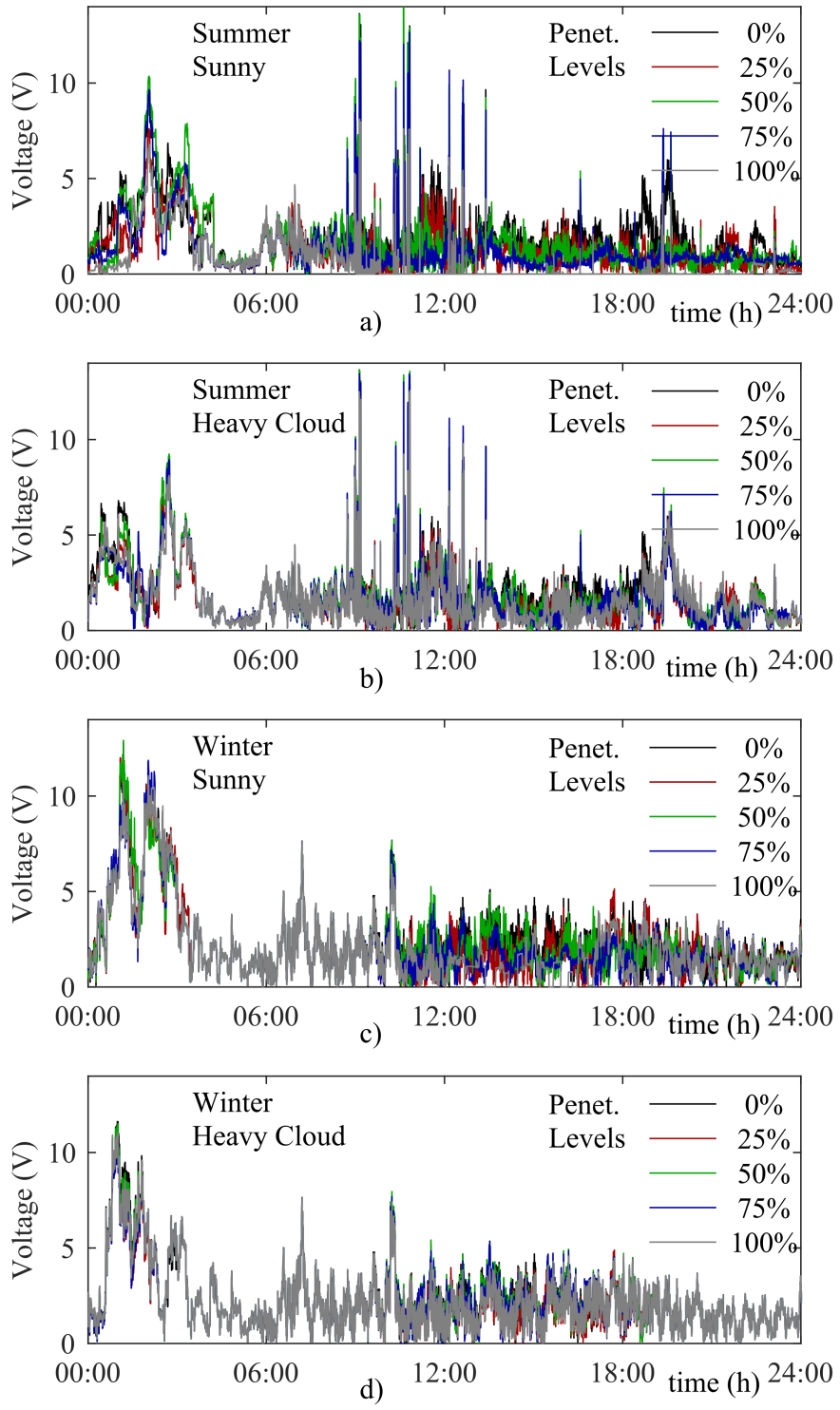

Fig. 7: Neutral voltage at the house placed in node 53 with different penetration levels $(0 \%, 25 \%, 50 \%, 75 \%$ and $100 \%)$. a) Summer sunny scenario. b) Summer heavy cloud scenario. c) Winter sunny scenario. d) Winter heavy cloud scenario.

\section{REFERENCES}

[1] F. M. Camilo, R. Castro, M. E. Almeida, and V. F. Pires, "Selfconsumption and storage as a way to facilitate the integration of renewable energy in low voltage distribution networks," IET Generation, Transmission Distribution, vol. 10, no. 7, pp. 1741-1748, 2016.

[2] R. H. Lasseter, "Microgrids," in 2002 IEEE Power Engineering Society Winter Meeting. Conference Proceedings (Cat. No.02CH37309), vol. 1, Jan 2002, pp. 305-308 vol.1.

[3] S. Barcellona, L. Piegari, V. Musolino, and C. Ballif, "Economic viability for residential battery storage systems in grid-connected pv plants," IET Renewable Power Generation, vol. 12, no. 2, pp. 135-142, 2018.

[4] T. Morstyn, A. Teytelboym, and M. D. Mcculloch, "Bilateral contract networks for peer-to-peer energy trading," IEEE Transactions on Smart Grid, vol. 10, no. 2, pp. 2026-2035, March 2019.

[5] P. Siano, G. De Marco, A. Rolán, and V. Loia, "A survey and evaluation of the potentials of distributed ledger technology for peer-to-peer transactive energy exchanges in local energy markets," IEEE Systems Journal, pp. 1-13, 2019.
[6] N. Liu, M. Cheng, X. Yu, J. Zhong, and J. Lei, "Energy-sharing provider for pv prosumer clusters: A hybrid approach using stochastic programming and stackelberg game," IEEE Transactions on Industrial Electronics, vol. 65, no. 8, pp. 6740-6750, Aug 2018.

[7] W. Liu, J. Zhan, and C. Y. Chung, "A novel transactive energy control mechanism for collaborative networked microgrids," IEEE Transactions on Power Systems, pp. 1-1, 2018.

[8] A. Pratt, D. Krishnamurthy, M. Ruth, H. Wu, M. Lunacek, and P. Vaynshenk, "Transactive home energy management systems: The impact of their proliferation on the electric grid," IEEE Electrification Magazine, vol. 4, no. 4, pp. 8-14, Dec 2016.

[9] Q. Huang, T. McDermott, Y. Tang, A. Makhmalbaf, D. Hammerstrom, A. Fisher, L. Marinovici, and T. Hardy, "Simulation-based valuation of transactive energy systems," IEEE Transactions on Power Systems, pp. $1-1,2018$.

[10] B. Celik, S. Suryanarayanan, R. Roche, and T. M. Hansen, "Quantifying the impact of solar photovoltaic and energy storage assets on the performance of a residential energy aggregator," IEEE Transactions on Sustainable Energy, pp. 1-1, 2019.

[11] N. K. Kandasamy, K. J. Tseng, and S. Boon-Hee, "Virtual storage capacity using demand response management to overcome intermittency of solar pv generation," IET Renewable Power Generation, vol. 11, no. 14, pp. 1741-1748, 2017.

[12] S. Riaz, H. Marzooghi, G. Verbič, A. C. Chapman, and D. J. Hill, "Generic demand model considering the impact of prosumers for future grid scenario analysis," IEEE Transactions on Smart Grid, pp. 1-1, 2018.

[13] B. Turnšek, I. Papic, and B. Blažic, "Influence of self-consumption on distribution network operation: the slovenian case," CIRED - Open Access Proceedings Journal, vol. 2017, no. 1, pp. 1822-1826, 2017.

[14] F. M. Camilo, R. Castro, M. E. Almeida, and V. Fernão Pires, "Assessment of overvoltage mitigation techniques in lowvoltage distribution networks with high penetration of photovoltaic microgeneration," IET Renewable Power Generation, vol. 12, no. 6, pp. 649-656, 2018.

[15] P. A. Leicester, C. I. Goodier, and P. N. Rowley, "Probabilistic analysis of solar photovoltaic self-consumption using bayesian network models," IET Renewable Power Generation, vol. 10, no. 4, pp. 448-455, 2016.

[16] A. Rogeau, T. Barbier, R. Girard, and N. Kong, "Evolution of electrical distribution grid sizing considering self-consumption of local renewable production," CIRED - Open Access Proceedings Journal, vol. 2017, no. 1, pp. 2275-2278, 2017.

[17] M. Farrokhabadi, B. V. Solanki, C. A. Canizares, K. Bhattacharya, S. Koenig, P. S. Sauter, T. Leibfried, and S. Hohmann, "Energy storage in microgrids: Compensating for generation and demand fluctuations while providing ancillary services," IEEE Power and Energy Magazine, vol. 15 , no. 5, pp. 81-91, Sep. 2017.

[18] U. Akram, M. Khalid, and S. Shafiq, "An improved optimal sizing methodology for future autonomous residential smart power systems," IEEE Access, vol. 6, pp. 5986-6000, 2018.

[19] M. Z. Degefa, H. Sæle, J. A. Foosnaes, and E. Thorshaug, "Seasonally variant deployment of electric battery storage systems in active distribution networks," CIRED - Open Access Proceedings Journal, vol. 2017, no. 1, pp. 1975-1979, 2017.

[20] J. von Appen and M. Braun, "Sizing and improved grid integration of residential pv systems with heat pumps and battery storage systems," IEEE Transactions on Energy Conversion, vol. 34, no. 1, pp. 562-571, March 2019.

[21] L. Martirano, G. Parise, G. Greco, M. Manganelli, F. Massarella, M. Cianfrini, L. Parise, P. di Laura Frattura, and E. Habib, "Aggregation of users in a residential/commercial building managed by a building energy management system (bems)," IEEE Transactions on Industry Applications, pp. 1-1, 2018.

[22] M. Ruiz-Cortes, E. G. Romera, R. A. Lopes, E. Romero-Cadaval, J. Martins, M. I. M. Montero, and F. Barrero, "Optimal charge/discharge scheduling of batteries in microgrids of prosumers," IEEE Transactions on Energy Conversion, pp. 1-1, 2018.

[23] N. G. Paterakis, O. Erdinç, I. N. Pappi, A. G. Bakirtzis, and J. P. Catalao, "Coordinated operation of a neighborhood of smart households comprising electric vehicles, energy storage and distributed generation," IEEE Transactions on Smart Grid, vol. 7, no. 6, pp. 2736-2747, Nov 2016.

[24] Royal Decree-Law 15/2018, October 5th, On Urgent Measures for Energy Transition and Consumer Protection., Spanish Government, 2018.

[25] Law 24/2013 of the Electric Sector. Electrical Energy Self-Consumption, Spanish Government, 2013. 
[26] Royal Decree 900/2015, October $9^{\text {th }}$. On Regulation of the Administrative, Technical and Economic Conditions for the Supply of Electricity and Production for Self-Consumption., Spanish Government, 2015.

[27] ADRES-CONCEPT, "(EZ-IF: Development of concepts for ADRES autonomous decentralized regenerative energy systems, project no. 815674). the project was funded by the austrian climate and energy fund and performed under the program ENERGIE DER ZUKUNFT." 2010.

[28] American Society of Heating, Refrigeration and Air-Conditioning Engineers, Inc., 2011 ASHRAE Handbook. 1791 Tullie Circle, N.E., Atlanta, GA 30329: ASHRAE, 2011.

[29] M. J. Sanjari and H. B. Gooi, "Probabilistic forecast of pv power generation based on higher order markov chain," IEEE Transactions on Power Systems, vol. 32, no. 4, pp. 2942-2952, July 2017.



Pablo Arboleya (SM'13) received the M.Sc. and Ph.D. (with distinction) degrees from the University of Oviedo, Gijón, Spain, in 2001 and 2005, respectively, both in Electrical Engineering. Nowadays, he works as Associate Professor in the Department of Electrical Engineering at the University of Oviedo, he is Managing Editor of the International Journal of Electrical Power and Energy Systems and holder of the Gijón Smart Cities Chair at the University of Oviedo. Presently his main research interests are focused in the micro-grid and smart-grid modeling and operation techniques, Internet of the Energy applications, railway traction networks simulation and combined AC/DC power flow algorithms.

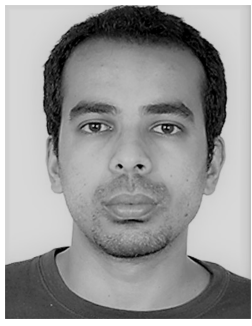

Arpan Koirala received his Master degree (2018) in Erasmus Mundus Master Course in Sustainable Transportation and Electrical Power Systems from consortium of University of Oviedo, Spain, La Sapienza, Rome, University of Nottingham, UK and Polytechnic Institute of Coimbra. He is currently pursuing his $\mathrm{PhD}$ degree from ESAT-ELECTA department of KU Leuven situated in Energyville, Genk. His area of interest are distribution system modeling, energy market and high scale integration of renewable resources.

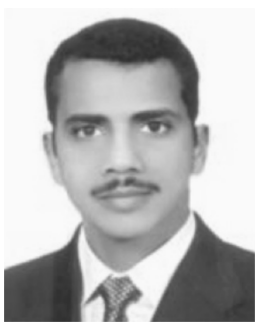

Bassam Mohamed received the M.Sc and Ph.D. degrees from the University of Oviedo, Gijón, Spain, in 2014 and 2018 respectively. He is now responsible of railway software development at LEMUR Research Group. His field of expertise has to do with the efficient development and implementation of algorithms for power systems analysis, specially those related to railway networks and unbalanced micro-grids. During the last years we developed several commercial software packages for electric network analysis and simulation.

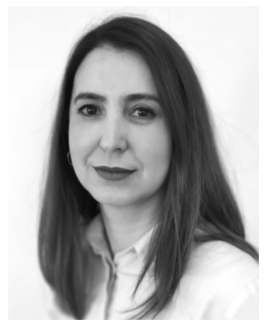

Cristina González-Morán (SM'15) received the M.Sc. and Ph.D. degrees from the University of Oviedo, Spain, in 2003 and 2010, respectively, both in electrical engineering. She is currently an Associate Professor with the Department of Electrical Engineering, University of Oviedo. She is the coordinator of the Electrical Energy Conversion and Power Systems Master Course. Her areas of interest include renewable energies, distributed generation and microgrids modeling, simulation, design, and optimization.

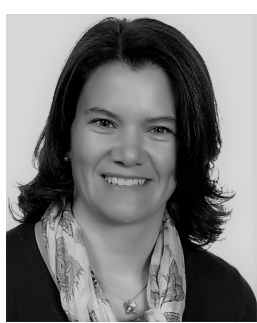

Lucía Suarez-Ramón received the M.Sc. degree in Electrical Engineering from the University of Oviedo, Gijón, Spain, in 1997. Nowadays, she works as Chief of Telemanagement System Infrastructure at EDP and she is pursuing her $\mathrm{PhD}$. at LEMUR Research Group at University of Oviedo. Her main research interests have to do with the smart operation of terminal distribution networks, networks analysis and simulation and failures detection. 